\title{
A Qualitative Study of Males' Perceptions about Causes of Eating Disorder
}

\author{
Karin Wallin 1*, Gunn Pettersen2, Tabita Björk ${ }^{3,4}$, Maria Råstam \\ ${ }^{1}$ Department of Clinical Science Lund, Child and Adolescent Psychiatry, Lund University, Lund, Sweden \\ ${ }^{2}$ Department of Health and Care Sciences, University of Troms $\varnothing$, The Arctic University of Norway, Troms $\varnothing$, \\ Norway \\ ${ }^{3}$ Department of Clinical Neuroscience, Psychiatry, Karolinska Institute, Stockholm, Sweden \\ ${ }^{4}$ Department of Health and Medical Science, Örebro University, Örebro, Sweden \\ Email: ${ }^{*}$ Karin.Wallin@med.lu.se
}

Received 8 August 2014; revised 4 September 2014; accepted 25 September 2014

Copyright (C) 2014 by authors and Scientific Research Publishing Inc.

This work is licensed under the Creative Commons Attribution International License (CC BY).

http://creativecommons.org/licenses/by/4.0/

(c) (i) Open Access

\begin{abstract}
Our knowledge about males' perceptions about causes of eating disorder is very limited, but can be useful in the treatment planning for males. The aim of this study was to describe how male former patients perceived causes of onset of their eating disorder. Fifteen males previously treated for eating disorders and now considering themselves as recovered where interviewed at ages 19 - 52. All interviews were recorded and analyzed qualitatively using a phenomenographic approach. Three categories of perceived causes of onset of eating disorders were found. The first category: self-dissatisfaction, was presented with three conceptions: "High achievements and demands", "Body-dissatisfaction" and "Low self-esteem". The second category: family environment, comprised the two conceptions: "Difficulty in family interaction and communication" and "Excessive expectations from family members". The third category was stressful events outside the family, and consisted of the three conceptions: "Bullying, bad situation at school", "Moving to new places/separation from friends" and "Societal ideals". Males' perceptions of causes of onset of their eating disorder were in many aspects similar to those earlier described for women. In treatment, it is important that the clinicians show a sincere interest in perceived causes, since it may facilitate a good working alliance with the patient.
\end{abstract}

\section{Keywords}

Eating Disorders, Males, Causes, Qualitative

\footnotetext{
${ }^{*}$ Corresponding author.
} 


\section{Introduction}

This study focuses of males' pre-history and perceived causes of onset of their eating disorders (ED). About 10\% of all cases of ED are found among males (Hoek \& van Hoeken, 2003). Strother, Lemberg, Stanford \& Turberville (2013) described males with ED as misunderstood, underdiagnosed and undertreated. This is a sad and serious statement that clearly warrants further research about males with ED, in order to improve treatment and chances of recovery. This study presents research on perceived causes of onset of ED in males in order to contribute to improved understanding of the reasons for developing ED-behavior amongst males.

The earliest clinical observations of ED were made by Richard Morton in 1689 (Silverman, 1990). He described two cases, a male and a female, with problematic eating, sadness and anxious care. Despite this and other historical data, the dominant research and clinical thinking about ED has taken a female perspective.

ED is generally understood as a multifactorial illness involving the interaction of biological, psychological and social factors (Striegel-Moore \& Bulik, 2007). For example, one biological risk factor identified is predisposition to obesity (Cooper, 1995; Treasure \& Holland, 1989, 1991) whereas weight concerns, as a result of thinness idealization, have been found as a psychosocial risk factor for ED (Keel \& Forney, 2013). Social risks include body dissatisfaction, bullying, problematic interaction in families or other personal traumas (Kent., Waller, \& Dagnan, 1999). Sociocultural body ideals stress body dissatisfaction in both males and females, and body dissatisfaction in turn increases the risk for ED (Stice \& Shaw, 2002). Males are occupied with building muscles and females are working to be thin (Andersen, Cohn, \& Holbrook 2000; Daniels \& Bridges, 2010). ED is overrepresented among female adolescents and young adults (Smink, Hoeken, \& Hoek, 2012), and some studies also suggest an overrepresentation of ED in homosexual males (Russell \& Keel, 2001; Connor, Johnsson, \& Grogan, 2004; Crisp, 2006) and among those suffering from a general psychiatric morbidity (Jacobi, Hayward, de Zwaan, Kraemer, \& Agras, 2004).

Risk factors, presented above, indicate a probability on a group level and should be distinguished from perceived causes, since perceived causes may be highly unrelated to risk factors or causes of ED on a group level. Surveying previous research focused on ED amongst women, a few studies were found on patients' perspectives of causes for developing an ED (Nilsson, 2007; Nevonen \& Broberg, 2000; Tozzi, Sullivan, Fear, McKenzie, \& Bulik, 2003). As far as we know, no previous studies exploring how males experience the cause or reasons why they developed ED. The closest reference is made by Nevonen \& Broberg (2000), highlighting the importance to listen to the patients' story, word by word at admission in order to adapt treatment in relation to their pre-history of ED. A lack of understanding of why males evolve ED seems to prevail.

The aim of this study was to describe how male former patients perceived causes of onset of their eating disorder.

\section{Methods}

Interviews and analyses were guided by a qualitative phenomenographic approach (Marton, 1981) in order to identify and describe the various causes that former patients expressed as their perceived causes behind their history of developing ED. This approach allows a focus on the individual's different ways of experiencing a particular phenomenon and still generates a description at a collective level in the form of distinct descriptive categories (Marton, 1981, 1992). Moreover, as the descriptive categories are derived from a fairly small group of people, capturing the individual differences are important in order to improve the future applicability of the descriptive categories to other groups (Marton \& Booth, 1997).

\section{Procedure and Participants}

Former patients eligible for participation in the study included 1) males 18 years of age or older; 2) patients with a previous DSM-IV (American Psychiatric Association, 1994), diagnosis of eating disorder; 3) patients who had completed their eating disorder treatment and recovered. All of them were recruited through special units for eating disorder in Sweden and Norway. The recruitment procedure included a written request to all units in the two countries asking therapists to contact their former patients if they fulfilled all three inclusion criterion above and inquire if they were interested to join the study. A total of 17 males were contacted. Of these, 15 responded positively and were contacted by the researchers and given information about the study. They all gave their written consent to participate. Given the disbursed geographical location of the participants, individual inter- 
views were carried out close to their homes. The interview guide was constructed by the authors to allow for a conversation about the participants' own perceptions of the causes of ED-onset. The interviews that lasted for about 1 - 2 hours and were carried out by one of the three authors (KW, TB, GP), and to reduce bias no author interviewed their own former patient. All interviews were recorded and transcribed verbatim and actual names were changed to secure anonymity. All quotes are presented with a fictive name, age at ED-onset, age at interview, and with diagnoses (e.g. Patrick, 14/24, AN).

A total of 15 males, aged between $19-52$ years (MD = 23 years), participated in an individual face-to-face interview. Of the participants, ten had experienced anorexia nervosa (AN), four had experienced bulimia nervosa (BN) and one had experienced an eating disorder not otherwise specified (EDNOS). The onset of their ED symptoms occurred between 10 and 21 years of age, and all had received treatment in the public health care system. The sample comprised individuals with a variety of occupations.

The study was approved by the Regional Ethical Committee for Medical and Health Care Research in Northern Norway and the Regional Ethical Review Board Uppsala, Sweden (2009-04-22, Reg. no: 118).

\section{Data Analysis}

The participants were asked to identify their perceived causes of their ED, and to share their reflections around the pre-history of their ED including aspects like how their social, family and personal situation functioned at time for onset.

Firstly, to obtain an overall picture, the authors listened to all of the interviews. The individual transcripts were compared with the recorded interviews during a second round of listening through the full material in order to confirm the accuracy of the text. Secondly, all statements related to the aim of the study, such as those related to perceived causes of onset, were marked and labeled. In the next step, all statements were arranged into conceptions, which were compared and preliminary grouped into descriptive categories, containing the conceptions.

The following step included exploring the similarities and differences between the preliminary descriptive categories, resulting in three non-overlapping descriptive categories and eight conceptions about perceived causes of ED-onset. In order to reach a general consensus in terms of labeling the conceptions and organizing the categories, the chosen statements were analyzed by all three interviewers and discussed until an agreement was reached.

\section{Results}

\subsection{General Impression of the Findings}

The first reflection concerns the willingness of the participants to talk about their own thoughts about causes of onset of ED. It was clear that some participants found participating in the interview difficult. This was related to the participant having avoided thinking about their history of ED post recovery.

The second reflection relates to a common pattern where nearly all participants had experienced dissatisfaction and conflicts in important areas of life, e.g., self-esteem, body image, family life and social interactions. In addition, shame related to the ED-symptoms and loneliness were dominant feelings never shared with parents or friends.

More specifically, participants described perceived causes of onset of ED in a total of 109 statements. These were labeled and sorted into three categories, i.e. 1) Self-dissatisfaction; 2) Family environment; and 3) Stressful events outside the family. Each category was further divided into eight conceptions describing the content of the category. Each conception was exemplified by two or more quotes.

\subsubsection{Self-Dissatisfaction}

The participants described how self-dissatisfaction became their drive for change in different domains of their lives. They demanded of themselves to always perform better; felt emotionally insecure, struggled with identity problems and had a strong desire to change their bodies or appearance. Expressions of self-dissatisfaction are presented in three conceptions: "High achievements and demands", "Body-dissatisfaction" and "Low self-esteem".

1) High achievements and demands

This first conception relates to how the interviewed males perceived that their low self-esteem would be im- 
proved by high achievements, resulting in very high demands of performance. They attained high achievements by setting high goals.

"I'm the oldest sibling in my family and with a family that often moved around, I often changed classes and felt a bit rootless. I mean, I adjusted very well to others but then I'm also very academically oriented, I quickly worked out a way to behave to fit in, to be someone else. I was a perfectionist too, I was hard on myself about academic performance and high achievements" (Alexander, 13/21, AN).

"The reasons for it (onset of ED) were my self-expectations on attaining high grades, overall high performance, and starting high-school, to achieve popularity, not only by knowledge acquisition. I really wanted to get better at things. It almost became a chase for improved performance and that's when it all flippedout. (Kim, 16/19, AN).

"No pleasure, only whipping myself to succeed" (Paul, 18/42, BN)

2) Body dissatisfaction

The second conception in this category relates to male body dissatisfaction. The males mentioned body dissatisfaction and the drive for changing their bodies as cause of onset. The dominant factor was overweight but some had other reasoning to body-dissatisfaction. For example, one boy suffered from severe acne and became almost suicidal before running into food regimes.

"Perhaps one can't eat certain things with acne. It got more and more extreme, I excluded more and more food stuff from my diet whilst not really knowing what I should eat" (Garry, 17/21, AN).

"What triggered it for me was a crush on a girl who wasn't in love with me, but was dating a guy who looked really fit with a lot more muscles, contrasting my tall, thin structure. Not knowing anything about diet, exercise or how to build up your body I started exercising really hard." (Mike, 17/36, AN).

3) Low self-esteem

This conception derives from the male's perceptions of not being good enough. Several participants expressed how they compared themselves with others in their social context and referenced the drive for change as a subsequent cause of the ED-onset. For some of the participants the low self-esteem resulted in extreme exercise. The quotes below exemplify how the males drive themselves to act upon their low self-esteem in order to change it:

"It's also related to a feeling of not being adequate, insecurity around your own identity. Seeing this other guy, who probably was a bit more 'macho' than I, I started thinking about my body and what is expected from a boy or a man, what attributes are desired by girls and women. It was an uncertainty about my identity, I was 17 years". (Mike, 17/36, AN).

"I worked out so much and got a kick out of not eating. I felt like I was the only one doing it right, the others were idiots. It almost generated a twisted self-image, it's like you seeing yourself as a hero or something". (Christopher, 11/21, AN).

\subsubsection{Family Environment}

In this category the males describe how aspects related to the family environment were experienced as contributing to onset of their ED. The males expressed a feeling of being neglected or discriminated among siblings and half-siblings by their parents or relatives. They also perceived high expectations on performance and achievements from their family. The family environment category consists of two conceptions: "Difficulty in family interaction and communication" and "Excessive expectations from family members".

1) Difficulty in family interaction and communication

In this conception the males have referred their onset of ED to conflicts inside the family, not limited to parents but including relatives. The participants told us about their feeling of loneliness and never thought about telling their parents or anybody else about their troubled life. The males quoted their experience of lack of attention:

"For example, not taking care of myself, not giving myself any credit-I got that from my home and applied it to myself without noticing. Those ideas were so established, that was just how it was. So I translated that 
into eating-the idea that I shouldn't have any needs. I trained myself to set limits to my needs" (Paul, $18 / 42, B N)$

"I think it could have been because I didn't get enough attention at home. My sister was ill too. She was suicidal between the ages of 14 and 16". (Christopher, 11/21, AN).

"It was difficult to be dedicated to something that I wasn't really interested in and felt I wouldn't go on with as a future job... but in my family you finish what you have started. So I began to focus on food and started throwing up" (Robert, 19/45, BN).

2) Excessive expectations from family members

In different ways, the conception of excessive expectations from family members was reported. Several participants referred the onset of their illness to their family and its characteristics of representing strict rules, sometimes in religious terms, sometimes through more vague expectations. They all had the implicit nature of the demands from their families in common.

“This outside pressure... I knew my big sister had done really well in high school. My grades weren't too bad, but she was pretty much a straight A student. So I decided I was going to get top marks for everything too". (Kim, 16/19, AN).

"My mum had problems with eating disorders when she was young, and so did my grandmother. My mum was the eldest of four sisters. Her family was a bit odd I guess, and she developed severe anorexia. I don't know if it is genetic but perhaps there is a tendency in your personality that can be put on you from your parents" (Alexander, 13/21, AN).

"After my parents' divorce, conflicts and competition with my half-siblings was prolonged. They were always the favorites, I felt humiliated and lonely. My artist work and body control was of extreme importance to me then". (Patrick, 14/24, AN).

"Expectations, demands and lack of gratification were always present. You had to keep on working very hard. It never seemed to have an end goal. You were never good enough”. (David, 19/52, BN).

\subsubsection{Stressful Events outside the Family}

This third category builds on perceptions of how the males experience externally imposed stress. They found themselves being criticized and judged as both individuals and for their body (the wrong body). The three conceptions "Bullying, bad situation at school", "Moving to new places/separation from friends" and "Societal ideals" are described below:

1) Bullying/bad situation at school

In this concept, males described their problems of shame due to bullying, social insecurity due to changes, and frustration of being judged by their appearance. But mostly they reference the experience of being bullied as a trigger with consequences for their whole social situation, influencing their behavior and as something that drove them to change.

"It started as early as First Grade, I was only seven. The kids called me 'girly'. I had really red lips as a child, so they teased me. They touched my lips and went on about me wearing lipstick... then they got going with my eyelashes saying 'you're using that weird stuff girls put on their eyelashes'” (Christopher, 11/21, $A N)$.

"I had been bullied for some years and couldn't live with the shame from that... and that's when I decided not to be fat anymore so I got rid of a couple of kilos when I was 10. I ate very little, extremely little, and exercised a lot. I guess I've never really had a normal relationship to food since then" (Owen, 10/31, $A N-B N)$.

"They teased me at school for both being fat and a dummy, I have dyslexia, and fell in to self-contempt, I developed a phobia for both classroom—and food situation at school (Philip, 15/31, AN).

2) Moving to new place/separation from friends

The unexpected, sometimes sad experience of leaving a well-known environment, moving to a new place, school and social life, is a commonly perceived cause of onset of ED. Feelings of being precarious in a social 
environment in general can be related to several of the concepts. The separation from friends and having to reestablish themselves in a new environment seems to have been particularly difficult.

“My mum moved a lot. I moved a lot. We've both had eating disorders. I think I will try to keep my kids in one place”. (Alexander, 13/21, AN).

"It began every time I changed school, the stress around finding friends it made me focus more on football. Sometimes however I had to change teams at the same time". (Oscar, 13/21, AN)

"I guess that was a time when I was pretty unstable, psychologically. My girlfriend had just left me-we had been together for a year". (Garry, 17/21, AN).

3) Societal ideals

Ideals coming from societal definitions about good appearance were often mentioned together with a number of other concepts and as such it could have a function of enforcing the development of the illness.

“I felt I wasn't good enough, I continuously compared myself with others, watched TV where the image of men is that they are all macho and I couldn't really relate". (Mike, 17/36, AN).

"I wanted to make myself cool, be popular, look good, I guess" (Kim, 16/19, AN).

\section{Discussion}

The aim of the present study was to describe how males perceived the causes of their ED-onset. Result shows that the males had experienced problems in different domains in life that they perceived have had a determining influence on their ED-onset. This results support the general opinion of ED understood as a multifactorial decease (Striegel-Moore \& Bulik, 2007).

Our study identified self-dissatisfaction as one of the three categories that participants found had caused their ED. Within the category of self-dissatisfaction, all three concepts of dissatisfaction; high demands, body-dissatisfaction, and low self-esteem have been previously reported in research on ED-onset among females (Nilsson, 2007; Tozzi et al., 2003).

Family environment was another category identified. This finding is in line with several other studies. For example, Nilsson (2007) identified excessive expectations from family members, as well as difficulty in family interaction and communication as reasons for onset. In the same direction, studies by Beresin, Gordon \& Herzog, (1989) and Tozzi et al., (2003) identified family dysfunction to be a perceived cause. Problematic interaction in families or other personal traumas are in addition included as risk factors for developing ED (Kent et al., 1999).

The third category, stressful events outside the family, was perceived as a cause of onset of ED. Examples related to bullying for not fitting the social ideal of appearance (e.g. being too thin, or too big) were referenced by the male participants. Sociocultural body ideals are previously reported in research as drivers to stress body dissatisfaction in both males and females. Body dissatisfaction in turn is believed to increase the risk for ED (Stice \& Shaw, 2002). None of the analyzed interviews indicated that the participants used excessive exercise for its own reason; all participants referenced psychosocial triggers pushing them into exaggerated physical change. This finding could be used in treatment planning, showing the need to offer additional support to those males, helping them to develop new coping strategies in specifically stressful situations.

The strength of this study is its originality as, to the best of our knowledge, being the first one to investigate how males experience the causes of their illness. Another strength is the use of phenomenographic approach and openended format, thus reducing possible biases from the authors' pre-understanding of possible experienced causes. An asset to the study was the fact that all patients appeared as highly committed to provide their stories. Finally, the study sample was sufficiently rich in variation. For example, it comprised individuals with different ages, diagnosis and duration of ED. These differences maximize variation and help to disclose similarities and differences in how the males understood the causes of their ED. The variation also strengthens the possibility that the males views of causes in this study, also are transferable to other males with a history of ED (Marton, 1981, 1992; Marton \& Booth, 1997).

\section{Conclusion}

The perceived causes of ED-onset in this study are largely in line with qualitative studies on females. Perceived 
causes may be clinically relevant as they may provide a gateway to cognitive beliefs which serves to maintain the ED. Also, the clinician's sincere interest in perceived causes may facilitate a good working alliance with the patient. Such an alliance may be particularly important in treating males, who disappointingly too often may feel misunderstood when seeking help (Strother et al., 2013).

\section{References}

American Psychiatric Association (1994). Diagnostic and Statistical Manual of Mental Disorders: DSM-IV (4th ed.). Washington DC.

Andersen, A., Cohn, L., \& Holbrook, T. (2000). Making Weight, Men’s Conflicts with Food, Weight, Shape \& Appearance. Carlsbad, CA: Gurze Books.

Beresin, E. V., Gordon, C., \& Herzog, D. B. (1989). The Process of Recovering from Anorexia Nervosa. Journal of the American Academy of Psychoanalysis, 17, 103-130.

Connor, M., Johnsson, C., \& Grogan, S. (2004). Gender, Sexuality, Body Image and Eating Behaviors. Journal of Health Psychology, 9, 505-515. http://dx.doi.org/10.1177/1359105304044034

Cooper, P. J. (1995). Eating Disorders and Their Relationship to Mood and Anxiety Disorders. In K. D. Brownell, \& C. G. Fairburn (Eds.), Eating Disorders and Obesity: A Comprehensive Handbook. New York: Guilford Press.

Crisp, A. (2006). Anorexia Nervosa in Males: Similarities and Differences to Anorexia Nervosa in Females. European Eating Disorders Review, 14, 163-167. http://dx.doi.org/10.1002/erv.703

Daniels, S., \& Bridges, S. K. (2010). The Drive for Muscularity in Men: Media Influences and Objectification Theory. Body Image, 7, 32-38. http://dx.doi.org/10.1016/j.bodyim.2009.08.003

Hoek, H. W., \& van Hoeken, D. (2003). Review of the Prevalence and Incidence of Eating Disorders. International Journal of Eating Disorders, 34, 383-396. http://dx.doi.org/10.1002/eat.10222

Jacobi, C., Hayward, C., de Zwaan, M., Kraemer, H. C., \& Agras, W. S. (2004). Coming to Terms with Risk Factors for Eating Disorders: Application of Risk Terminology and Suggestions for General Taxonomy. Psychological Bulletin, 130, 19-65. http://dx.doi.org/10.1037/0033-2909.130.1.19

Keel, P. K., \& Forney, K. J. (2013). Psychosocial Risk Factors for Eating Disorders. International Journal of Eating Disorders, 46, 433-439. http://dx.doi.org/10.1002/eat.22094

Kent, A., Waller, G., \& Dagnan, D. (1999). A Greater Role of Emotional than Physical or Sexual Abuse in Predicting Disordered Eating Attitudes: The Role of Mediating Variables. International Journal of Eating Disorders, 25, 159-167. http://dx.doi.org/10.1002/(SICI)1098-108X(199903)25:2<159::AID-EAT5>3.0.CO;2-F

Marton, F. (1981). Phenomenography—Describing Conceptions of the World around Us. Instructional Science, 10, $177-200$. http://dx.doi.org/10.1007/BF00132516

Marton, F. (1992). Phenomenography and “the Art of Teaching All Things to All Men”. International Journal of Qualitative Studies in Education, 5, 253-267. http://dx.doi.org/10.1080/0951839920050305

Marton, F., \& Booth, S. (1997). Learning and Awareness. Mahwah, NJ: Lawrence Earlbaum Associates.

Nevonen, L., \& Broberg, A. G. (2000). The Emergence of Eating Disorders: An Exploratory Study. European Eating Disorders Review, 8, 279-292. http://dx.doi.org/10.1002/1099-0968(200008)8:4<279::AID-ERV348>3.0.CO;2-J

Nilsson, K. (2007). Causes of Adolescent Onset Anorexia Nervosa: Patient Perspectives. Eating Disorders, 15, $125-133$. http://dx.doi.org/10.1080/10640260701190642

Russell, C. J., \& Keel, P. K. (2001). Homosexuality as a Specific Risk Factor for Eating Disorders in Men. International Journal of Eating Disorders, 31, 300-306. http://dx.doi.org/10.1002/eat.10036

Silverman, J. A. (1990). Anorexia Nervosa in the Male: Early Historic Cases. In A. E. Anderssen (Ed.), Males with Eating Disorders (pp. 13-22). New York: Brunner-Routledge.

Smink, F. R. E., van Hoeken, D., \& Hoek, H. W. (2012). Epidemiology of Eating Disorders: Incidence, Prevalence and Mortality Rates. Current Psychiatry Reports, 14, 406-414. http://dx.doi.org/10.1007/s11920-012-0282-y

Striegel-Moore, R. H., \& Bulik, C. M. (2007). Risk Factors for Eating Disorders. American Psychologist, 62, 189-198. http://dx.doi.org/10.1037/0003-066X.62.3.181

Stice, E., \& Shaw, H. E. (2002). Role of Body Dissatisfaction in the Onset and Maintenance of Eating Pathology. Journal of Psychosomatic Research, 53, 985-993.

Strother, E., Lemberg, R., Stanford, S. C., \& Turberville, D. (2013). Eating Disorders in Men: Underdiagnosed, Undertreated, and Misunderstood. In L. Cohn, \& R. Lemberg (Eds.), Current Findings on Males with Eating Disorders (pp. 13-22). New York: Routledge. 
Tozzi, F., Sullivan, P. F., Fear, J. L., McKenzie, J. M., \& Bulik, C. M. (2003). Causes and Recovery in Anorexia Nervosa: The Patient's Perspective. International Journal of Eating Disorders, 33, 143-154. http://dx.doi.org/10.1002/eat.10120

Treasure, J. L., \& Holland, A. J. (1989). Genetic Vulnerability to Eating Disorders: Evidence from Twin and Family Studies. In H. Remschmidt, \& M. Schmidt, (Eds.), Child and Youth Psychiatry: European Perspectives (pp. 59-68). New York: Hogrefe \& Huber.

Treasure, J. L., \& Holland, A. J. (1991). Genes and the Etiology of Eating Disorders In P. McGuffin, \& R. Murray (Eds.), The New Genetics of Mental Illness (pp. 198-211). Oxford: Butterworth-Heinemann. http://dx.doi.org/10.1016/B978-0-7506-0029-3.50018-2 
Scientific Research Publishing (SCIRP) is one of the largest Open Access journal publishers. It is currently publishing more than 200 open access, online, peer-reviewed journals covering a wide range of academic disciplines. SCIRP serves the worldwide academic communities and contributes to the progress and application of science with its publication.

Other selected journals from SCIRP are listed as below. Submit your manuscript to us via either submit@scirp.org or Online Submission Portal.
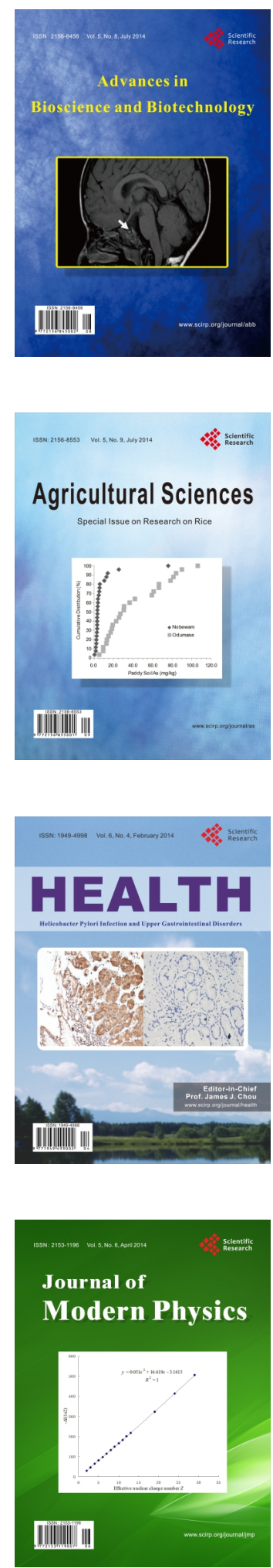
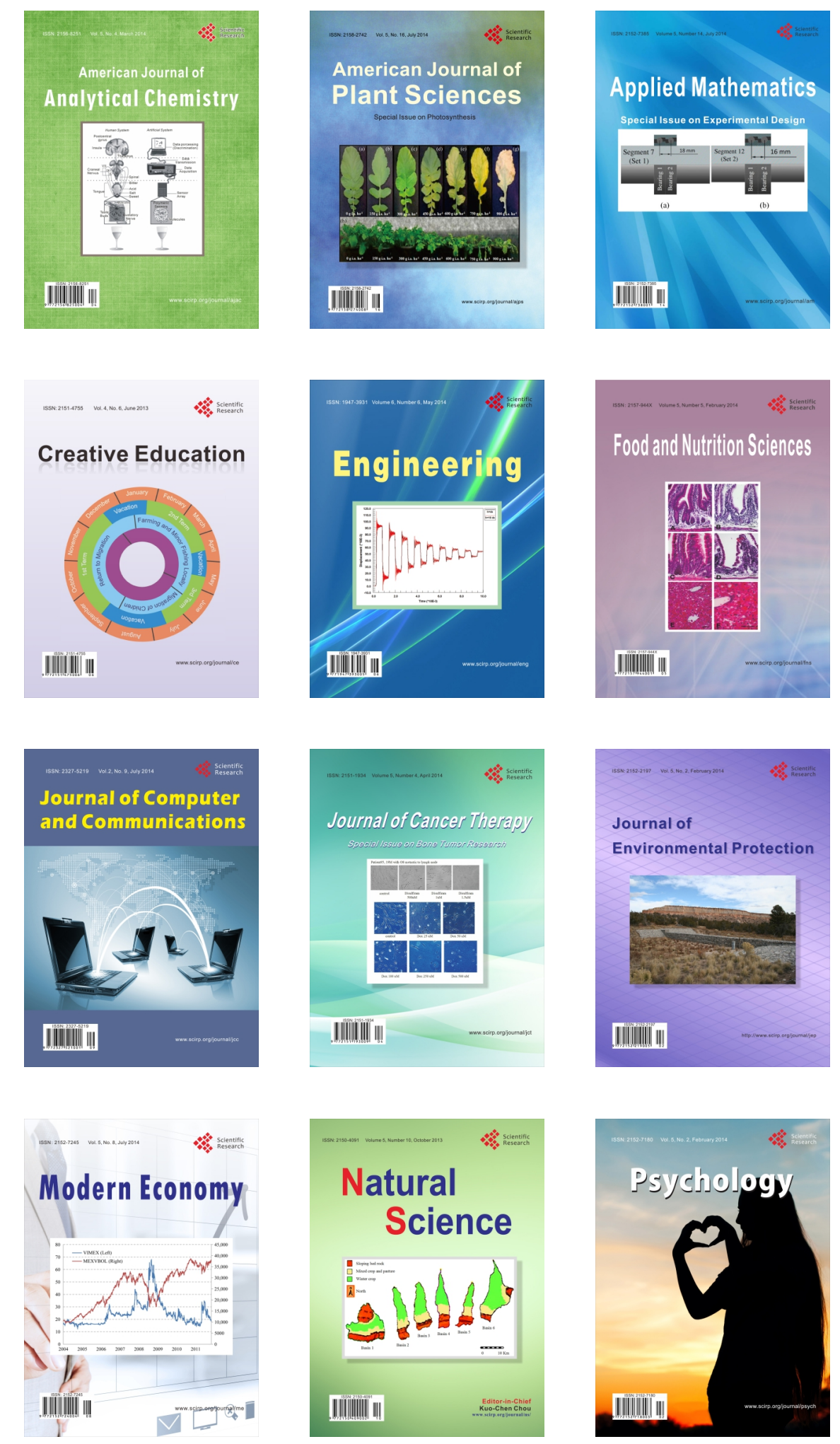